\title{
FORECASTING THE INFLUENCE OF TRAFFIC DEMAND ELASTICITY ON THE EFFECTIVENESS OF ROAD INVESTMENTS - ANALYSIS RESULTS FOR THE KRAKOW CITY RING ROAD SYSTEM
}

\begin{abstract}
The paper is devoted to simulation analysis of the phenomenon often observed in contemporary urban areas, i.e. the so-called induced traffic resulting from the improvement of travel conditions in the road network. On the basis of analyzes carried out in the simulation model of Krakow, it was shown, as exemplified by the postulated changes in the urban peripheral system of Krakow -i.e. the construction of the western section of the so-called $3^{\text {rd }}$ city ring road and further narrowing of the so-called $2^{\text {nd }}$ city ring road - the appearance of additional car traffic may affect the output image of the city's transport system. Taking into account the elasticity of road demand has a significant impact on the resultant parameters of the network operation and can significantly change the final assessment of the effectiveness of a given road investment - and also provide important premises for a long-term strategy of shaping the city road system.
\end{abstract}

Keywords: induced traffic, demand elasticity, Krakow, macrosimulation model

\section{Introduction}

A commonly observed phenomenon in modern cities is the fact that efforts and actions taken to expand the supply of the transport system are not able to keep up with the constantly increasing transport demand. Despite multi-million investment expenditures in the development of the road network (i.e. supply), these profits are in the long run significantly or completely "consumed" by the constantly increasing traffic (i.e. demand), which leads to the exhaustion 
of capacity of the system - and consequently, the deterioration in the efficiency of its functioning, measured, for example, by time or speed of travel.

This phenomenon is well known in the theory and practice of road transport systems as so-called induced traffic which - apart from demographic and economic factors - may be caused by the improvement and development of road infrastructure itself. Initial improvement of traffic conditions in the network, resulting from the widening of roads, construction of multi-level junctions etc., encourages increased transport activity and results in increased traffic on the network. In urban conditions, where the transport system often operates in a state of near saturation, even a small increase in traffic may lead to the limit of capacity being exhausted in critical parts of the road network - and this in turn to an increase in congestion and a significant decrease in travel speed in a wider area of the city (or speaking colloquially, to an even worse traffic jams in the city). It leads to a paradox in which investment activities bring only a short-term improvement of travel conditions, and in the long run can be counterproductive, bringing a significantly (or completely) different effect from the intended one (this is known in transport economics as the so-called Lewis-Mogridge law).

Therefore, it is necessary to use analytical methods and tools that will describe and forecast processes occurring in transport systems of modern cities - e.g. simulation models that predict the distribution of travel flows in the network and provide information on the expected performance and functioning of the transport system. According to the Blue Book developed by JASPERS, simulation models are the basic and key tool in traffic analysis and forecasts, and should be used to evaluate any investment projects that could bring about fundamental changes in the road network. The obtained simulation results - travel flows in the network, their parameters related to distance and travel times (vehicle-km and vehicle- $h$ ), average speed, etc. - are the basis for further assessment of economic and financial efficiency and indicators calculated under the analyzes of costs and benefits. Taking into account the variability of the state of demand depending on the state of supply can therefore significantly change the final assessment of a given road project and decide on its final (in) effectiveness.

This article presents the results of analyzes in the model of the Krakow transport system, carried out using macro-simulation methods and tools. The aim of the work is to show - on the example of postulated changes in the urban road system of Krakow (western sections of the so-called $2^{\text {nd }}$ and $3^{\text {rd }}$ city ring roads) - differences in the results of road investment analyzes that arise due to the phenomenon of potential elasticity of demand (i.e. road inducement or suppression) depending on traffic conditions in the road network.

\section{Elasticity of road demand as a measure of the phenomenon of the induced traffic}

In describing the phenomena of the induced (or suppressed) movement, caused by the improvement (or deterioration) of traveling conditions in the network, 
an analogy is used to the law of supply and demand, i.e. the classical dependence in the world of economics. The level of travel demand is not a constant value, but it reacts depending on the so-called general travel costs in the network, and this relationship can be presented in the form of a curve describing the elasticity of road demand as a function of costs on the supply (road) network. This parameter is defined as the quotient between the difference in traffic intensity (i.e. the number of vehicles or vehicle-kilometers in a given unit of time) to the difference in the measure of traffic conditions (i.e. change of travel times, level of freedom of movement, etc.) - i.e. as a difference between the values after and before the implementation of the road investment. The demand elasticity rate can be represented by the equation (1), which is a description of this relation that can be used in simulation models:

$$
\varepsilon_{i j}^{W_{x}}=\frac{\left(\frac{d_{i j}^{W_{x}}-d_{i j}^{W_{0}}}{d_{i j}^{W_{0}}}\right)}{-\left(\frac{t_{a, i j}^{W_{x}}-t_{a, i j}^{W_{0}}}{t_{a, i j}^{W_{0}}}\right)},
$$

where:

$\varepsilon_{i j}^{w_{x}}$ - demand elasticity rate [-] for investment project (variant) $W x$,

$d_{i j}^{W_{x}}, d_{i j}^{W_{0}}$ - number of vehicles [vehicles/hour] traveling from the traffic zone $i$ and to the traffic zone $j$, respectively in: in the investment variant $W x$ and in the non-investment variant $W_{0}$

$t_{a, j}^{W_{x}}, t_{a, i j}^{W_{0}}$ - car travel times (actual) in the network [min] from the traffic zone $I$ and to the traffic zone $j$, respectively in the investment variant $W x$ and in the non-investment variant $W_{0}$.

According to the above equation, the decrease in the cost of travel in the network - i.e. reduction of travel times - will result in a positive change in the number of vehicles between the given regions (the induced traffic); while the increase in travel costs - i.e. increasing travel times - will mean a negative change in the number of vehicles (the suppressed traffic).

The phenomenon of the induced traffic in the short time horizon (up to several years) results from changes of travel routes in the network (taking over traffic from other routes), changes in the means of travel (taking over traffic from public transport) and changes in travel time (e.g. taking over traffic from other times of the day). In the long-term, changes resulting in the induced traffic are shaped additionally by factors such as changes in sources and destinations and changes in the level of mobility (i.e. average number of trips) - which result from long-term demographic and economic changes initiated by the development of road infrastructure (e.g. changes in spatial development). A review of scientific and research literature indicates that the demand elasticity rate can be estimated at roughly $0.3-0.8$ in short-term terms, and to 1.0-1.2 in long-term terms ${ }^{1}$; in simulation analyzes it is recommended to use values of the order of $0.5-0.8$ to describe the effects of short-term phenomenon of the induced traffic ${ }^{2}$. These values can also refer

\footnotetext{
1 A. Szarata, Modelowanie podróży wzbudzonych oraz tłumionych zmianą stanu infrastruktury transportowej, Monograph, Cracow University of Technology, Cracow 2013.

2 T. Litman, Generated traffic and induced travel. Implications for Transport Planning, Victoria Transport Policy Institute, 2017.
} 
not only to the number of journeys, but also to the measure of operation performed by all vehicles in the road network - that is, the product of the so-called vehicle-kilometers (or vehicle-miles).

Taking into account the elasticity of road demand is of fundamental importance for assessing the effectiveness of road investments. In many research works, it is emphasized that analyzes conducted on the assumption of a rigid level of road demand tend to overestimate the benefits of road projects, and even small changes in the volume of demand (several percent) can have a very large impact on the results of the final cost-benefit analysis. This is due to the fact that the induced traffic causes a further increase in travel costs for all users in the road network, which has already achieved a fairly high level of saturation - and it brings relatively small benefits, as the induced traffic mainly concerns optional journeys. As experience and planning practice shows, depending on network conditions and volume of traffic, taking into account the elasticity of demand at the level of 0.5 - i.e. value, which is supported by many empirical observations - may lead not only to a significant reduction of estimated profits from the investment project, but in some cases change the result of the final efficiency analysis to negative ${ }^{3}$.

\section{Methodology and assumptions of analyzes - Krakow transport system model}

For further analytical works, showing what differences may appear in the assessment of a given road project as a result of taking into account the demand elasticity factor, a simulation transport model Krakow created with the aid of the PTV VISUM software will be used. This model is a macroscopic representation of the transport system in the area of the city of Krakow and neighboring municipalities (the area of the Krakow agglomeration) and was created as part of the Comprehensive Traffic Research carried out in Krakow in 2013.

The simulation analysis will be carried out for two variants regarding the transformation of the city's perimeter system in Krakow, and more specifically - in the western part of the city. According to the strategic intentions, the target peripheral system of Krakow is to consist of four bypass roads, each of which is to play a different function depending on the importance and location in the network, adopted design solutions, the share of local and long-distance traffic, etc.

Among the intentions and postulates related to the city's peripheral system of Krakow, there are two projects of key importance for the functioning of the transport system in the whole city:

- Construction of the western section of the so-called $3^{\text {rd }}$ city ring road, i.e.: Zwierzyniecka route, Pychowicka route and Lagiewnicka route (ZPL route) in the GP road class with a section of $2 \times 2$ or $2 \times 3$ (between nodes). In the future, the $3^{\text {rd }}$ city ring road will be the basic communication frame (axis) for car trips within the city, ensuring efficient perimeter linkage of large Krakow settlements and outgoing traffic from downtown areas;

3 D. Coombe, Induced traffic: what do transportation models tell us?, Transportation 1996, 23. 


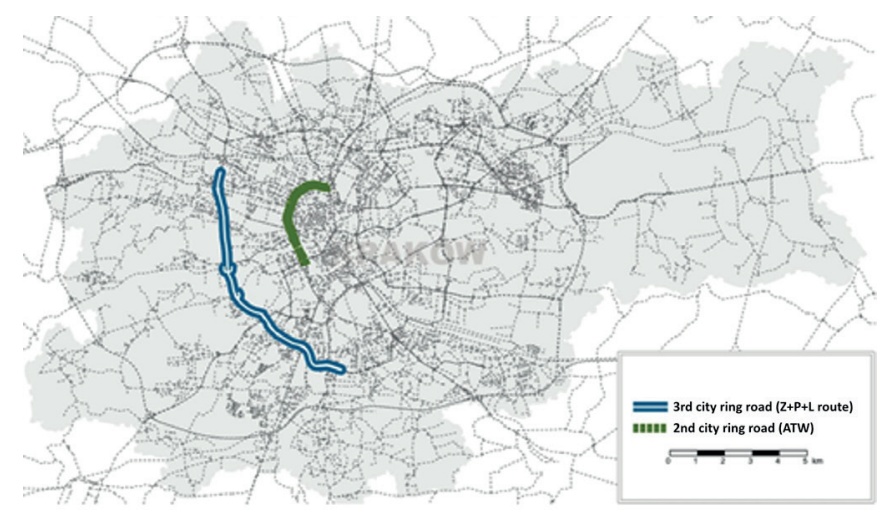

Figure 1. Analyzed investment projects - western sections of the so-called $3^{\text {rd }}$ and $2^{\text {nd }}$ Krakow city ring roads

Source: own elaboration based on: Krakow's Movement Model

- Narrowing of the western section of the so-called $2^{\text {nd }}$ city ring road, i.e. the route of Aleja Trzech Wieszczow (ATW), and potentially also the Debnicki Bridge and al. Konopnicka - degradation to the class $Z$ road and leaving one lane for car traffic in each direction. In the present state, the $2^{\text {nd }}$ city ring road, running in the city center of Krakow, must carry significant flows of local and long-distance traffic, which due to the lack of alternative connections (e.g. the $3^{\text {rd }}$ city ring road) must pass through the center of Krakow.

These are complementary and related projects, and at the same time their implementation will lead to a fundamental change in travel conditions across the entire transport network of Krakow. Therefore, it is necessary to forecast their potential effects in the context of the induced traffic, which may adversely affect the expected improvement in the conditions of car travel. It will also help to answer the question of the direction in which the Krakow road system should be shaped in order to obtain more tangible results.

The simulation analysis of the above projects was carried out for the forecasting model 2025 at the morning rush hour (7:30-8:30). The following simulation scenarios (variants) were assumed in the works:

- $W_{0}$ non-investment option for 2025;

- $W_{1}$ investment option for 2025, in which the western section of the third beltway was implemented - Zwierzyniecka route, Pychowicka and Lagiewnicka;

- $W_{2}$ investment option for 2025 , i.e. variant W1 extended additionally with narrowing of the western section of the $2^{\text {nd }}$ ring road - on the section from Rondo Grunwaldzki to the node with ul. Wit Stwosz - up to 1 lane in each direction (for general traffic).

For comparison, works in variants $W_{1}$ and $W_{2}$ were carried out with the assumption of a rigid level of demand - i.e. the number of motor vehicles (in each travel relation in Krakow) the same as in the $W_{0}$ variant, and taking into account the elasticity of demand - i.e. the number of motor vehicles in variant $W_{1}$ and $W_{2}$, which varies depending on travel times in the network loaded according to equation (1), with a coefficient $\varepsilon_{i j}^{w_{x}}$ of 0.50 or 0.75 . 


\section{Results of simulation analyzes - effects of induced traffic}

Table 1 presents the result parameters obtained for individual simulation scenarios. Figure 2 is a graphical representation of the phenomenon of the induced traffic according to simulation analyzes in the Krakow road network, obtained by overlapping simulation results in investment variants with rigid $\left(\varepsilon_{i j}^{w_{x}}=0\right)$ and flexible $\left(\varepsilon_{i j}^{w_{x}}=0.50\right.$ or 0.75$)$ number of car trips. In other words, the travel streams visible on it can be interpreted as a potential underestimation of the traffic volume in the case when investment variants $\left(W_{1}, W_{2}\right)$ are set to a fixed (rigid) level of road demand.

Table 1. Simulation results - parameters of the road network functioning in the scale of the entire model area

\begin{tabular}{|c|c|c|c|c|c|c|c|}
\hline \multirow{2}{*}{ Variant 2025} & \multirow{2}{*}{$\begin{array}{c}\text { Demand } \\
\text { elasticity } \\
\text { rate }\end{array}$} & \multirow{2}{*}{$\begin{array}{c}\begin{array}{c}\text { Number } \\
\text { of trips - } \\
\text { total }\end{array} \\
\begin{array}{c}\text { [vehicle/ } \\
\text { hour] }\end{array} \\
\end{array}$} & \multirow{2}{*}{$\begin{array}{c}\text { Number } \\
\text { of trips - } \\
\text { induced } \\
\text { traffic } \\
\begin{array}{c}\Delta \text { [vehicle/ } \\
\text { hour] }\end{array} \\
\end{array}$} & \multicolumn{2}{|c|}{$\begin{array}{l}\text { Operating parameters } \\
\text { of the road network }\end{array}$} & \multirow{2}{*}{$\begin{array}{c}\text { Erosion } \\
\text { of the initial } \\
\text { reductionin } \\
\text { [hr] by } \\
\text { the induced } \\
\text { traffic } \\
\Delta \text { [vehicle- } \\
\text { hour] [\%] }\end{array}$} & \multirow{2}{*}{$\begin{array}{c}\text { Average } \\
\text { speed }\end{array}$} \\
\hline & & & & [vehicle-km] & $\begin{array}{l}\text { [vehicle- } \\
\text { hour] }\end{array}$ & & \\
\hline$W_{0}$ & - & 78673 & - & 958997 & 20159 & - & 47.6 \\
\hline \multirow{3}{*}{$\begin{array}{l}W_{1} \\
\text { (ZPL route) }\end{array}$} & 0 & 78673 & - & 950245 & 19155 & - & 49.6 \\
\hline & 0.50 & 80048 & +1375 & 968359 & 19757 & $+602(60 \%)$ & 49.0 \\
\hline & 0.75 & 80736 & +2063 & 977408 & 20071 & $+916(91 \%)$ & 48.7 \\
\hline \multirow{3}{*}{$\begin{array}{l}W_{2} \\
\text { (ZPL route, } \\
\text { ATW } \\
\text { narrowing) }\end{array}$} & 0 & 78673 & - & 956232 & 19550 & - & 48.9 \\
\hline & 0.50 & 79432 & +759 & 967279 & 19911 & $+361(59 \%)$ & 48.6 \\
\hline & 0.75 & 79811 & +1138 & 972791 & 20098 & $+548(90 \%)$ & 48.4 \\
\hline
\end{tabular}

Source: own elaboration

For both investment variants $\left(W_{1}\right.$ and $\left.W_{2}\right)$, the analysis conducted on the assumption of a rigid level of road demand shows that the implementation of the assumed scenarios brings a clear improvement: the new route (ZPL route) takes over a significant number of vehicles from the wider area of the city, especially parallel sections of the $4^{\text {th }}$ city ring road (A4 motorway) and $2^{\text {nd }}$ city ring road (ATW) and the traffic in the section of the ZPL route in both variants ranges in the order of 3500-4000 vehicles/hour. There is also visible the effect of changes on the $2^{\text {nd }}$ city ring road (ATW), where the traffic decreases only slightly in variant $W_{1}$ (about 3600 vehicles/hour in the cross section of Debnicki Bridge), but clearly decreases as a result of the narrowing of the route in option $W_{2}$ (around 2200 vehicles/hour). The implementation of the investment brings clear changes in travel parameters across the entire network: the time spent by all vehicles in the network decreases by $500\left(W_{2}\right)$ to $1.000\left(W_{1}\right)$ vehicle-hours, and the average speed of travel increases to $48.9 \mathrm{~km} / \mathrm{h}\left(W_{2}\right)$ and even $49.6 \mathrm{~km} / \mathrm{h}\left(W_{1}\right)$.

Taking into account the elasticity of road demand, to a large extent, changes the image of the analysis results obtained. In option $W_{1}$, the construction of the ZPL 
route without any further interference in the road system initially brings a marked reduction in travel times in many relations in the city, which results in increased traffic in the wider Krakow area. Figure 2 shows how the induced traffic is not concentrated only along the ODG route itself (additional 300-400 vehicles/hour in cross-section), but also appears on other sections of the network - i.e. both access roads and parallel connections, i.e. $4^{\text {th }}$ and $2^{\text {nd }}$ city ring roads. Depending on the adopted elasticity of demand, this means the appearance of an additional 1400-2100 vehicles in the network, and the average speed of travel in the network is lower by approx. $0.5-1.0 \mathrm{~km} / \mathrm{h}$ than in the variant of rigid road demand.

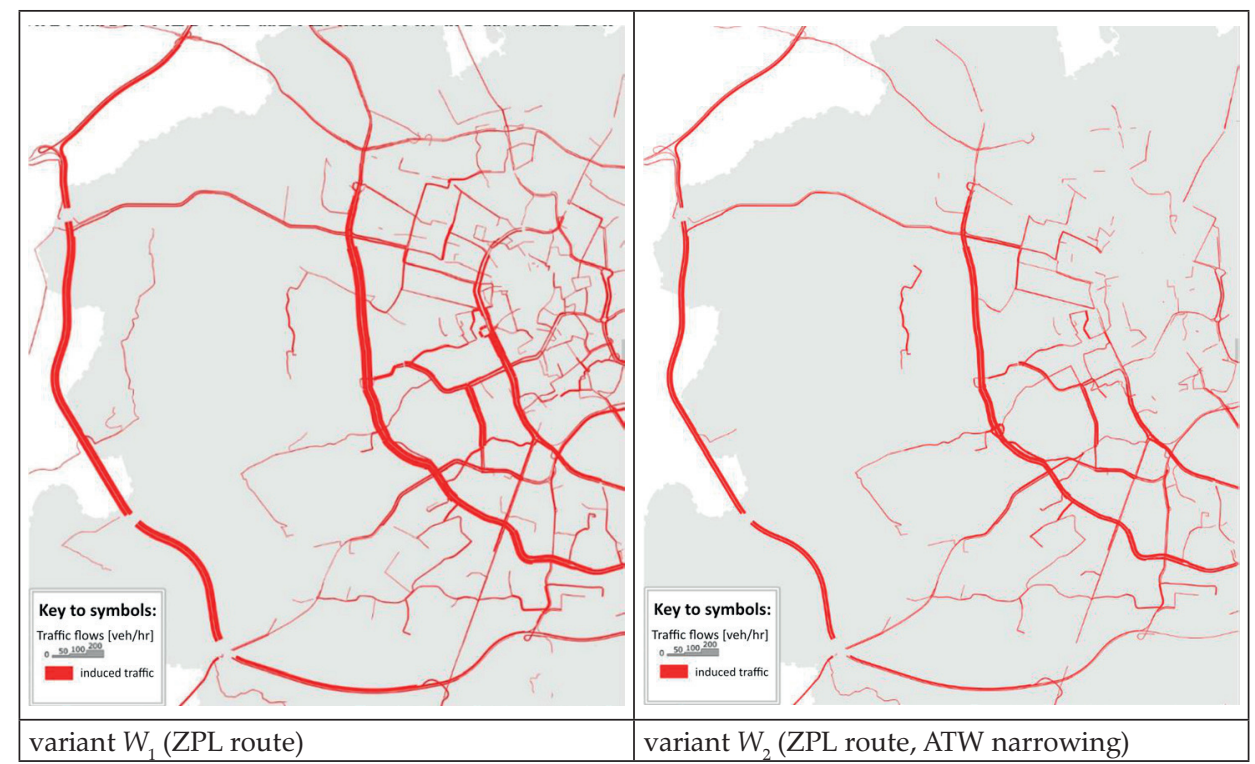

Figure 2. Simulation results - a graphical representation of traffic flows induced in the Krakow's road network

Source: own elaboration based on: Krakow transport system model

In option $W_{2}$, the construction of the ZPL route along with the ATW constriction also means (initially) positive changes in travel times in the network, but the scale of induced traffic is clearly lower than in the variant $W_{1}$. Induced traffic appears mainly along the $3^{\text {rd }}$ city ring road (additional 200-250 vehicles/hour in section) and $4^{\text {th }}$ city ring road, but it virtually completely disappears on the narrowed section of the $2^{\text {nd }}$ city ring road. You can also see the limitation of the network effect the induced traffic appears mainly in the southern part of Krakow, but it is only visible to a small extent in the central (and northern) area of Krakow. The demand elasticity results in the appearance of an additional around 700-1100 vehicles in the network, and the fall in the average speed compared to the rigid demand variant is only about $0.2-0.5 \mathrm{~km} / \mathrm{h}$. 


\section{Conclusions}

The results of the above analyzes show how important in the assessment of the effectiveness of road projects in cities may be the lack of taking into account the reaction (elasticity) on the side of road demand for the initial improvement of network traffic conditions. In the analyzed variants of $W_{1}$ and $W_{2}$, the elasticity of demand at the level of $0.50-0.75$ means that the initially estimated reduction of time spent by all vehicles in the network, i.e. the number of vehicle-hours, can be lower by as much as 60-90\%; There is also a clear increase in network loading, i.e. the number of vehicle-kilometers. Taking into account changes in these parameters must therefore be important for further analysis of costs and benefits, which in turn will affect the final assessment of economic and financial efficiency.

The conclusions for the long-term strategy of shaping the Krakow road system are also important. It can be seen that the results of the variant $W_{1}$ reflect the paradox often observed in modern cities: the implementation of the western section of the $3^{\text {rd }}$ city ring road without further interference in the road system will not result in the planned relieve of $2^{\text {nd }}$ or $4^{\text {th }}$ city ring roads, where the released capacity reserves can be quickly "filled" by increased traffic car. In option $W_{2}$, further narrowing of the $2^{\text {nd }}$ city ring road will not only significantly reduce the car traffic along the ATW corridor, but will also reduce the scale of traffic induction in the area of the city center of Krakow.

A step-wise transformation of the Krakow road system according to the $W_{2}$ variant, i.e. construction of the $3^{\text {rd }}$ city ring road and further narrowing of the $2^{\text {nd }}$ city ring road, seems to be the optimal variant - allowing on the one hand the improvement of accessibility and speed (times) of travel in many travels in the area of Krakow; on the other hand - durable reduction in traffic load, especially in the city center.

This work was created as part of the research grant RID I-62 entitled "Principles of traffic forecasting including other means of transport", awarded by NCBiR and GDDKiA (contract No. DZP/RID-I-62/11/NCBR/2016).

\section{References}

Coombe D., Induced traffic: what do transportation models tell us?, Transportation 1996, 23. Goodwin P., Empirical evidence of induced traffic, Transportation 1996, 23.

JASPERS, Niebieska Ksiegga. Infrastruktura Drogowa, Ministry of Development, July 2015.

Litman T., Generated traffic and induced travel. Implications for Transport Planning, Victoria Transport Policy Institute, 2017.

Szarata A., Modelowanie podróży wzbudzonych oraz tłumionych zmiana stanu infrastruktury transportowej, Monograph, Cracow University of Technology, Cracow 2013.

Szarata A., Together with: Krakowski Model Ruchu, Cracow University of Technology, 2014.

Williams H.C.W.L., Moore L.A., The appraisal of highway investments under fixed and variable demand, Journal of Transport Economics and Policy 1990, 25(5).

\section{Corresponding authors}

Arkadiusz Drabicki can be contacted at: adrabicki@pk.edu.pl

Andrzej Szarata can be contacted at: aszarata@pk.edu.pl 